\title{
How to Evaluate the Coordination of Green Economy, Education Development, and Technological Innovation? Take China as Example
}

\author{
Junqi Wu and Kui Zhang (iD \\ Faculty of Artificial Intelligence in Education, Central China Normal University, No. 152 Luoyu Road, Wuhan, Hubei, China \\ Correspondence should be addressed to Kui Zhang; erikzk@163.com
}

Received 18 November 2021; Revised 15 December 2021; Accepted 23 December 2021; Published 20 January 2022

Academic Editor: Baogui Xin

Copyright (C) 2022 Junqi Wu and Kui Zhang. This is an open access article distributed under the Creative Commons Attribution License, which permits unrestricted use, distribution, and reproduction in any medium, provided the original work is properly cited.

\begin{abstract}
The coordination of green economy, education development, and technological innovation is of great significance for reversing the trend of ecological environmental deterioration and promoting high-quality economic development. This study first designs the indicator system of green economy, education development, and technological innovation, then uses the entropy method to calculate the comprehensive level of green economy, education development, and technological innovation of 30 provinces and cities in China, and finally uses the coupling coordination model to measure the coordination level among them. The research shows that, first, the comprehensive level of green economy, education development, and technological innovation in 30 provinces and cities in China showed a rising trend from 2005 to 2016, but there were some regional differences in their levels. Second, the coordination level of green economy, education development, and technological innovation in different regions of China was in a rising trend from 2005 to 2016, but in 2005, they were extremely uncoordinated. Also, the coordination level of green economy, education development, and technological innovation in most regions of China grew very slowly from 2005 to 2010 but showed a rapid increase from 2011 to 2016 . The coordination level of green economy, education development, and technological innovation in eastern China was visibly higher than that of the central region. The coordination level of the central region was higher than that of the northeast region, and the coordination level of the northeast region was higher than that of the western region. Finally, the limitations of this paper are summarized and proposed the direction of future research.
\end{abstract}

\section{Introduction}

China has made great achievements in economic development since the reform and opening up in 1978, with an average annual economic growth rate of over 9\%. In 2020, China's GDP exceeded 100 trillion yuan, ranking second in the world. However, serious ecological and environmental problems have emerged in the process of China's rapid economic development. The serious environmental pollution has not only caused serious economic losses but also caused serious damage to the health of citizens, leading to the increasingly strong call for the government to speed up environmental governance. With increasingly severe environmental pollution, China is also facing increasing downward pressure in the economic development.
According to statistics, China's GDP growth rate in 2015 was $7.04 \%$, but the growth rate dropped to $5.95 \%$ in 2019 . In order to cope with the increasingly severe environmental pollution and increasing economic downward pressure, the Chinese government has proposed to accelerate the transformation and upgrading of economic development, especially to vigorously develop the green economy to cope with the increasingly serious environmental pollution, requiring local governments at all levels to increase efforts to implement the concept of green development. In addition, the Chinese government has also proposed to develop education and technological innovation to cope with the increasing downward pressure on economic growth. In 2019, the investment of research and development $(\mathrm{R} \& \mathrm{D})$ reached 2.21436 trillion yuan, an increase of 246.57 billion yuan or 
$12.5 \%$ than last year. The R\&D investment accounted for $2.23 \%$ of GDP. In 2019, China's investment in education reached 5,017.8 billion yuan, accounting for more than $4 \%$ of GDP. The average length of education of Chinese people is increasing. With China's expansion in the enrollment of undergraduate and graduate students, the number of graduates from the university in China is growing every year. The number of graduates each year in China has been more than 7 million since 2014. The number reached 8.47 million in 2020. So the graduates provide a rich high-quality workforce for China's economic transformation. At the same time, the latest achievements of the Chinese government in the field of technological innovation are also emerging, such as high-speed railway, mobile payment, big data, and artificial intelligence, which are more and more applied to people's lives.

China has made remarkable progress in green economy, education development, and technological innovation in recent years, thanks to the Chinese government's continuous investment in these areas as well as substantial policy support. The fundamental goal of the Chinese government to develop green economy is to reverse the worsening trend of environmental pollution and realize the harmonious coexistence between human and nature. Since the development of education and technological progress requires a large amount of capital investment, in particular, it needs financial support from the government, and the development of green economy can provide the Chinese government with appropriate financial support for education development and technological innovation. Chinese government's investment and policy support in education development and technological innovation will not only ease the pressure of economic downturn but also help develop green economy. And technological progress can directly provide power for the development of green economy. This is mainly because green economy is an environmentfriendly economic development model. Education development can not only provide the high-quality labor force for the development of green economy but also provide the high-quality labor force for the development of technological innovation, while technological progress can directly provide power for the development of green economy. Therefore, green economy, educational development, and technological innovation are not isolated from each other but interact with each other. It is of great practical significance to analyze the relationship between green economy, education development, and technological innovation in order to reverse the worsening trend of environmental pollution, promote educational development, and enhance the endogenous power of economic development through technological progress and education development. However, few studies have analyzed the relationship between green economy, educational development, and technological innovation. In addition, as the largest developing country in the world, the analysis of the relationship among green economy, education development, and technological innovation in different regions of China has certain reference significance for helping other developing countries to accelerate the transformation and upgrading of economic development and better develop education and science and technology. Therefore, this study designed an evaluation index system of green economy, education development, and technological innovation, then measured the comprehensive level of the development of green economy, education development, and technology innovation of 30 provinces and cities from 2005 to 2016 by using the entropy method, and finally used the coordination model to analyze the coordination of relationship among green economy, education development, and technological innovation.

The content of the second part is a literature review, which is mainly the research and analysis of the relationship among green economic, education development, and technological innovation. The content of the third part introduces the research method used in this study, design of index system of green economy, education development, and technological innovation and data source. The fourth part uses the model to measure the comprehensive development level of green economy, education development, and technological innovation in 30 provinces and cities and analyzes the coupling coordination level among the three and the coupling coordination development differences between regions. The last part of this study puts forward the research conclusions and illustrates the shortcomings of this study and the future research direction.

\section{Literature Review}

\subsection{Relationship between Green Economy and Education} Development. At present, there are few related studies on green economy and education development, but there are a lot of literature studies on economic growth and education development. These researches basically support that education development has a positive role in promoting economic growth. Most of the studies on the impact of education on economic growth are based on human capital theory $[1,2]$. Human capital theory is that the physical capital refers to the capital on the material products, including factories, machinery, equipment, raw materials, land, currency, and other securities, and the human capital is embodied in the person's capital, namely to producers to carry on the education. School education can effectively improve the workers' human capital level to promote economic growth $[3,4]$. The theory of human capital has also been verified in the practice of China's rapid economic growth in the past 40 years. In the past 40 years, China's education has made great progress, which has provided a large number of high-quality workers for the development of China's economy. And most of the studies also verify the progress of education to economic development of the positive influence [5]. Among them, some scholars analyzed the relationship between the vocational education and economic growth in Chongqing and found that Chongqing's vocational education and economic development complemented each other. The greater per capita gross domestic product is, the more the graduates of vocational education will be. When the economy is relatively backward, the economic situation has a great impact on the number of vocational education graduates. When 
economic development is good, the influence is significantly reduced [6]. Some scholars have analyzed the role of education in economic growth in East Asia and found that there is a two-way causal relationship between education and economic growth. The higher the level of economic development is, the greater the demand for a better and higher education system will be [7]. Other scholars used the time series data of Pakistan from 1980 to 2011 to test the relationship between higher education and economic growth in Pakistan by means of cointegration test and causality test and found a two-way causal relationship between higher education and economic growth in Pakistan [8]. In addition, the contribution of higher education to economic growth increased significantly after the establishment of the Higher Education Commission of Pakistan in 2002 [8]. Based on literature reading, it is found that there are many kinds of literature directly studying education and economic growth, but relatively few researches analyzing green economy and education development. Gao et al. analyzed the role of higher education in the development of green economy and found that higher education played an important role in the construction of green economy [5]. In addition, green GDP is more sensitive to changes in higher education than traditional GDP [5]. Song and Xie constructed a human capital measurement model based on China's provincial panel data from 2001 to 2017 and analyzed the impact of employees' education level, per capita physical capital, green labor participation rate, and green jobs on economic growth [9]. On the whole, these studies are conducive to the research of this study. However, there are few works of literature directly analyzing the relationship between green economy and education development, while there are relatively few works of literature linking green economy, education development, and technological innovation to analyze the coordination level of the three.

\subsection{Relationship between Green Economy and Technological} Innovation. As for the relationship between green economy and technological innovation, on the one hand, most studies support the view that technological innovation can promote green economy development, mainly because it is an environmentally friendly way to develop the green economy and technological innovation can promote transformation and upgrading of the traditional mode of economic development, and reduce the environmental pollution problems appeared in the process of economic development. For example, Liu and Dong took 278 prefecture-level cities in China as examples to measure green economy efficiency (GEE) from 2003 to 2017 by using the data enveloping analysis game cross efficiency model and found that the intensive effect of technological innovation is significant, which can significantly improve GEE [10]. Some scholars used the data from 1990 to 2013 at the national level provided by OECD to evaluate econometric models by using the dynamic panel method and found that sustainable technology transfer and sustainable innovation promote green growth [11]. In addition, some scholars took 28 organizations of economic cooperation and development (OECD) as an example to analyze the impact of technological innovation on green growth by using data from 2000 to 2014 and found that technological innovation in product production and processing is conducive to green growth, and technological innovation in the field of energy production and transmission is harmful to green growth [12]. On the other hand, there are few works of literature directly analyzing how green economy affects technological innovation at present because the fundamental goal of developing green economy is to improve the ecological environment. But there are many works of literature analyzing how environmental regulation affects technological innovation, among which the most famous one is Porter's hypothesis. According to Porter's hypothesis, environmental regulation can promote enterprises to carry out more innovative activities, and these innovations will improve the productivity of enterprises, which can offset the cost brought by environmental protection, and the profitability of enterprises in the market and the product quality [13, 14]. Many scholars have tested Porter's hypothesis. For example, Fang et al. took the national special monitoring of business plan as a quasinatural experiment and used the enterprise data from 2004 to 2009 to study the impact of environmental regulation on enterprise innovation by the difference-in-difference method. The results show that the national special regulated enterprise program promotes the innovation of regulated enterprises [15]. In addition, Yuan et al. examined the impact of environmental regulation on technological innovation by using panel data of 28 manufacturing industries from 2003 to 2012 and found that environmental regulation has a significant promoting effect on technology research patent results and technology transformation into new products in China's manufacturing industry [16]. Based on these findings, we believe that as the government encourages the development of green economy, it can strengthen the supervision of the ecological environment, which will promote environmental polluting enterprises to speed up technological innovation.

2.3. Relationship between Education Development and Technological Innovation. In recent years, China has made great progress in the field of technological innovation. The achievements such as high-speed railway, mobile payment, big data, and cloud computing have been widely used in people's lives. In addition, China has also made great progress in education. On the one hand, that is how education development affects the technological innovation. With the further development of technological innovation, the education development in the role of promoting the development of technological innovation is more and more important. This is mainly because the development of technological innovation is ultimately on the basis of talents [17], and the education development can provide a large number of high-quality talents for scientific and technological innovation [18]. However, there are few studies on the relationship between education development and 
technological innovation. Among them, some scholars proposed the business engineering surgical technologies (BEST) teaching method and found that BEST proves to be a global talent incubator, connecting students to high-quality education, despite the boundary of system and economy. This revolutionary approach generates viable and innovative ideas that may lead to significant technology transfer and lead to future interdisciplinary mixed surgical education programs and career paths [18]. Zhou and Luo used the sample data from 1997 to 2015 in China and the vector autoregression (VAR) model to study and find that the investment in higher education is an important source and driving force of technological innovation [19]. Xiao and Mao used the data of 31 provinces in China, applied the spatial Durbin model (SDM) to explore the impact of graduate education on technological innovation and its spatial effect, and found that graduate education has a positive impact on technological innovation [20]. On the other hand, technological innovation also can promote the education development, mainly because the results of these technological innovations can be applied in the field of education and reform traditional education. Especially in recent years, the development of technology such as the Internet promotes the rapid development of online education and thus promotes the development of education. The wide application of smart education and other education modes in schools are supported by solid technological innovation achievements. In addition, the application of big data technology and virtual reality technology has promoted the reform of the traditional education model in the era of big data [21, 22].

\section{Design of Research Methods}

3.1. Comprehensive Level Measurement of Green Economy, Education Development, and Technological Innovation. The entropy value method is a widely used method in the objective weight method. To a certain extent, it increases the significance of index resolution, reduces the subjectivity of human beings and the overlap of information among multiple index variables, and is suitable for the comprehensive evaluation of multiple indexes [23]. For this reason, this study uses the entropy method to calculate the comprehensive level of green economy, education development, and technological innovation. The specific formulas are as follows:

First of all, the original data need to be standardized to eliminate the impact caused by different measurement units and dimensions of indicators $[24,25]$, as follows:

$$
\begin{aligned}
& \text { positive indicator : } y_{i j}=\frac{\left[x_{i j}-\min \left(x_{i j}\right)\right]}{\left[\max \left(x_{i j}\right)-\min \left(x_{i j}\right)\right]}, \\
& \text { negative indicator }: y_{i j}=\frac{\left[\max \left(x_{i j}\right)-x_{i j}\right]}{\left[\max \left(x_{i j}\right)-\min \left(x_{i j}\right)\right]},
\end{aligned}
$$

where $x_{i j}$ denotes the sample value and $\max \left(x_{i j}\right)$ and $\min \left(x_{i j}\right)$, respectively, denote the maximum and minimum values in the sample data.
Then, the index weight is calculated as follows:

$$
\begin{aligned}
p_{i j} & =\frac{y_{i j}}{\sum_{i=1}^{n} y_{i j}}, \quad e_{j} \\
& =\left[\frac{-1}{\ln (n)}\right] \sum_{i=1}^{n} p_{i j} \ln p_{i j}, \\
\mathrm{w}_{\mathrm{j}} & =\frac{\left(1-\mathrm{e}_{\mathrm{i}}\right)}{\sum_{\mathrm{i}=1}^{\mathrm{n}}\left(1-\mathrm{e}_{\mathrm{i}}\right)} .
\end{aligned}
$$

Finally, the comprehensive level of green economy, education development, and technological innovation is calculated, respectively. The calculation formula is as follows:

$$
U=\sum_{i=1}^{n} w_{i j} y_{i j}, \quad \sum_{i=1}^{n} w_{i j}=1,
$$

where $P_{i j}$ represents the weight of the indicator, $e_{j}$ represents the entropy value of the indicator, $w_{j}$ represents the weight of the indicator, and $U$ represents the comprehensive level of green economy education and technological innovation.

3.2. Coordinate Coupling Measurement. As the above analysis shows that green economy, education, and technological innovation influence each other, the relationship between them shows the characteristics of coupling. Coupling originally comes from physics. It refers to the interaction and influence between two or more systems. This study further analyzes the coupling coordination relationship among green economy, education development, and technological innovation through the coupling coordination model. The specific calculation formula is as follows:

$$
\begin{aligned}
& A=\frac{\left(U_{1} U_{2} U_{3}\right)}{\left[\left(U_{1}+U_{2}+U_{3}\right) / 3\right]}, \\
& C=A^{\mathrm{k}},
\end{aligned}
$$

In equations (6) and (7), $k=3, U_{1}, U_{2}$, and $U_{3}$ represent the comprehensive level of green economy, education development, and technological innovation, respectively. $C$ represents their coupling; the bigger the $C$, which means the coupling between them is higher, the better the synergy effect; when $C=0$, green economy, the development of education, and technological innovation of the coupling are the smallest, and they are in the independent state; and when the $C=1$, the coupling level of green economy, education development, and technological innovation reaches its peak; they are in a state of orderly development. However, when the level of green economy, education development, and technological innovation are low, a high coupling degree can also be obtained. Based on the modification of formula (6), the modified calculation formula is as follows: 


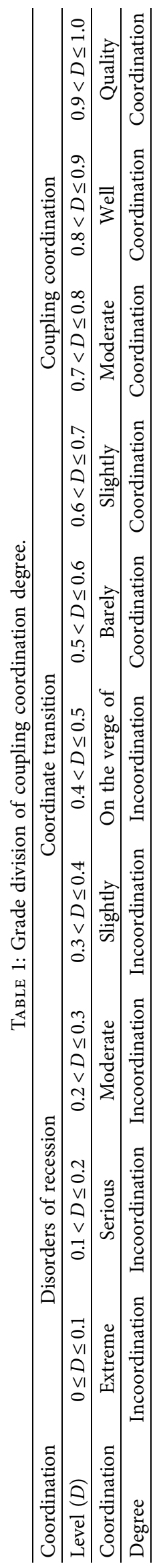


TABLE 2: Index system of green economy, education development, and technological innovation.

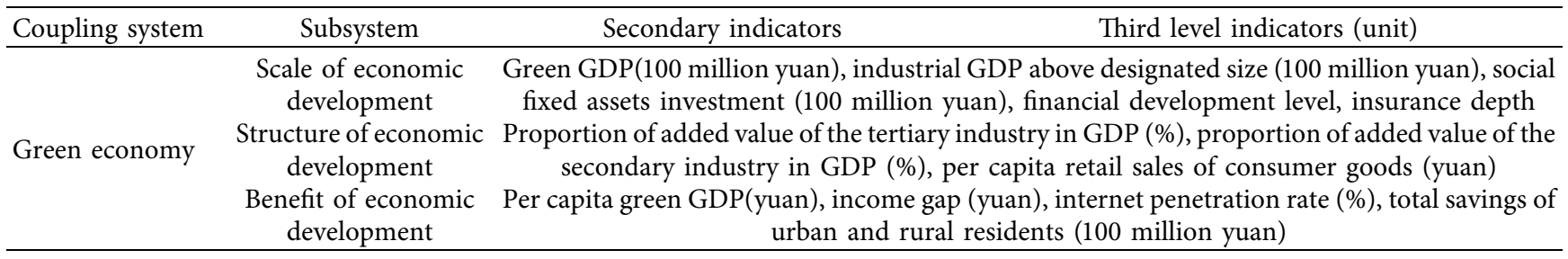

Enrolment rates at all levels of education

Educational opportunities

The proportion of continuing education and vocational education in the working population

Student-teacher ratio

Education expenditure per student

Education expenditure as a percentage of fiscal expenditure

Educational infrastructure
Education development
Area per student

Average number of books per student

School building area per student

Graduation rate

Quality of education
Enrolment rate of preschool education (\%), primary education (\%), middle and high school education (\%), higher education (\%)

Proportion of students in adult higher non-academic education (\%), proportion of students in secondary vocational education (\%)

Pre-school student-teacher ratio (\%), elementary student-teacher ratio (\%), junior high school studentteacher ratio (\%), college student-teacher ratio (\%)

Education expenditure per elementary school student (yuan), education expenditure per junior high school student (yuan), education expenditure per student for ordinary colleges and universities (yuan)

The proportion of pre-school education expenditure in fiscal expenditure (\%), the proportion of primary education expenditure in fiscal expenditure (\%), the proportion of junior and senior high school education expenditure in fiscal expenditure (\%)

Area for pre-school students $\left(\mathrm{m}^{2}\right)$, area for elementary school students $\left(\mathrm{m}^{2}\right)$, area for junior and high school students $\left(\mathrm{m}^{2}\right)$, area for college students $\left(\mathrm{m}^{2}\right)$

Average number of books for preschool students (volumes), average number of books for elementary school students (volumes), average number of books for middle and high school students (volumes), average number of books for college students (volumes)

Average school building area of preschool students $\left(\mathrm{m}^{2}\right)$, average school building area of primary school students $\left(\mathrm{m}^{2}\right)$, average school building area of junior and high school students $\left(\mathrm{m}^{2}\right)$, average school building area of college students $\left(\mathrm{m}^{2}\right)$

Primary school graduation rate (\%), junior high school graduation rate (\%) percentage of primary school freshmen receiving pre-school education (\%) Literacy rate of population over 15 years old (\%), average years of education of population over 6 years old (years)

\begin{tabular}{ccc}
\hline & $\begin{array}{c}\text { Technological } \\
\text { innovation } \\
\text { investment }\end{array}$ & $\begin{array}{c}\text { The full-time equivalent of R\&D personnel per 10,000 people, the proportion of R\&D } \\
\text { expenditure in GDP (\%), the proportion of enterprises with R\&D institutions (\%), the internal } \\
\text { expenditure of R\&D expenditure of large and medium-sized high-tech enterprises (10,000 } \\
\text { yuan) }\end{array}$ \\
$\begin{array}{c}\text { Technological } \\
\text { innovation }\end{array}$ & $\begin{array}{c}\text { Technological } \\
\text { innovation output } \\
\text { Technological } \\
\text { innovation effect }\end{array}$ & $\begin{array}{c}\text { Number of scientific papers (papers), number of patent authorizations (items), technology } \\
\text { market turnover (100 million yuan) }\end{array}$ \\
& $\begin{array}{c}\text { New product sales revenue (ten thousand yuan), export of high-tech products accounted for } \\
\text { delivery value (100 million yuan), energy consumption per unit GDP (ton of standard coal/ten } \\
\text { thousand yuan), labor productivity (ten thousand yuan/person) }\end{array}$ \\
\hline
\end{tabular}




$$
\begin{aligned}
t & =\delta U_{1}+\varepsilon U_{2}+\eta U_{3}, \\
D & =C \times \mathrm{t} .
\end{aligned}
$$

In equations (8) and (9), $T$ is the comprehensive evaluation index that can reflect the overall synergistic effect of green economy, education development, and technological innovation. $\delta, \varepsilon$, and $\eta$ are the undetermined coefficients. This study sets $\delta=\varepsilon=\eta=1 / 3$. $D$ is the degree of coupling coordination. The larger the value of $D$ is, the higher the degree of coupling coordination between green economy, educational development, and technological innovation is, and the better the level of coordination among them will be.

In order to effectively evaluate the coupling coordination degree of green economy, education development, and technological innovation, this study classifies the coupling coordination degree of green economy, education development, and technological innovation by referring to relevant studies [26, 27] (see Table 1).

\subsection{Design of Index System of Green Economy, Education} Development, and Technological Innovation. This study is based on the principle of systematization, integrity, scientificity, and data availability of the index system design. The index system of green economy, education development, and technological innovation is designed, respectively. First of all, the development of green economy not only includes the growth of the economy scale but also the improvement of the economic structure and the increase of economic efficiency from the reference literature [28-30]. 12 indicators such as green GDP (100 million yuan) and gross industrial product above designated size (100 million yuan) were selected to design the indicator system of green economy from these three dimensions which are the scale of economic development, the structure of economic development, and the benefit of economic development. Second, the comprehensive development of education, first of all, is to ensure that all citizens have equal access to education, fair education opportunities are the premise of sustainable development of education, and then, we need to ensure the high-quality development of education from the two aspects of education infrastructure and education quality [31-33] indicators such as preschool education enrollment rate (\%) is selected to design an indicator system of education development from the three dimensions of educational opportunity, educational infrastructure, and educational quality based on relevant literature $[34,35]$. Finally, as for technological innovation, the direct expression of technological innovation ability is the effect of technological innovation, and the effect of technological innovation is often determined by the input and output of technological innovation. So 11 indexes such as the population proportion that involved college graduates and, above in economic activity, GDP per capita, technology allocated proportion of funding, and Internet penetration are selected to construct the index system of technological innovation (see Table 2) from the three dimensions of the technological innovation investment, technological innovation output, and technological innovation achievements after the reference for related researches [36-38].

3.4. Data Resources. All the index data are from the China Statistical Yearbook (2006-2017), China Statistical Yearbook of Education (2006-2017), China Statistical Yearbook of Science and Technology (2006-2017), and regional statistical bulletins. All the calculation results of the data in this study are reserved with three decimal places.

\section{Results}

4.1. Overall Evaluation of Regional Green Economy, Education Development, and Technological Innovation. The development of the Chinese green economy, education, and the comprehensive level of technological innovation from 2005 to 2016 can be calculated according to the formula (1-5). Only some of the results (see Table 3 ) are listed as space is limited. Then, 30 provinces and cities of China are divided into four different regions such as eastern region, northeast region, central region, and western region. We can intuitively find the development and change of green economy, education development, and technological innovation in different regions in China from 2005 to 2016.

It can be seen from Table 3 that the comprehensive level of green economy, education development, and technological innovation in 30 provinces and cities in China from 2005 to 2016 showed a rising trend. First of all, in terms of the development level of green economy in the whole country, the comprehensive level of green economy in China was 0.162 in 2005, but it increased to 0.816 in 2016. Second, in terms of the comprehensive development level of education, China's education level was 0.156 in 2005 and increased to 0.810 in 2016. Finally, as for the level of technological innovation, China's technological innovation level was 0.122 in 2005 and increased to 0.827 in 2016 . From the growth trend of green economy, education, and technological innovation, it can be found that from 2005 to 2016, the development of green economy, education, and technological innovation is basically synchronous, but it can still be found from Table 3 that there are some regional differences in the levels of green economy, education development, and technological innovation in different regions of China.

Figure 1 is produced based on the results of Table 3 in order to visually show the growth of green economy, education development, and technological innovation in different regions from 2005 to 2016. It can be seen from Figure 1 that before 2011, the development level of technological innovation in the eastern region was lower than that of green economy and education development. After 2011, the overall level of technological innovation in the northeast region was higher than that of green economy and education development before 2012. However, after 2012, the technological innovation level in the northeast region is lower than the development level of green economy and education. In addition, from 2005 to 2016, the development level of technological innovation in central and western 


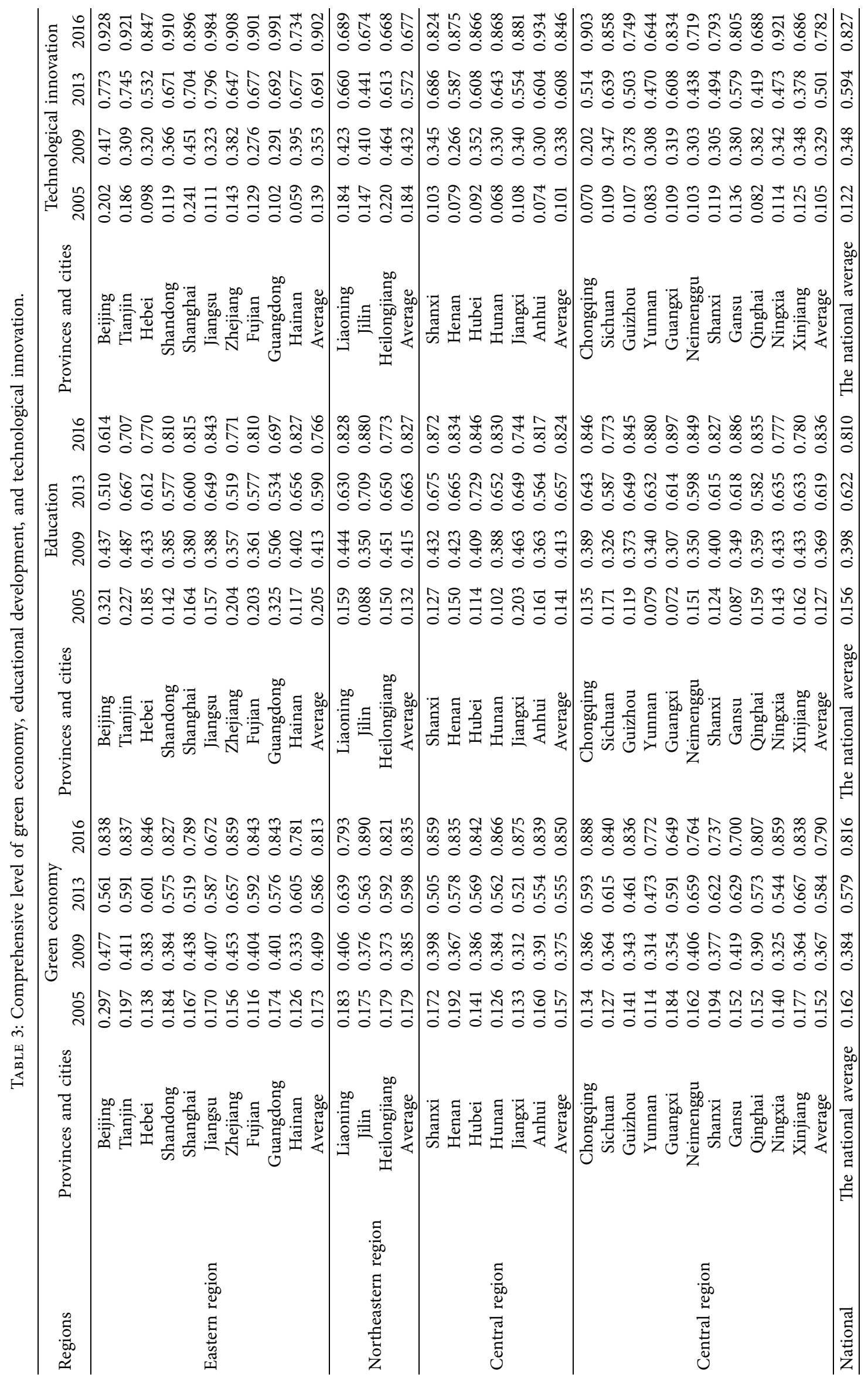



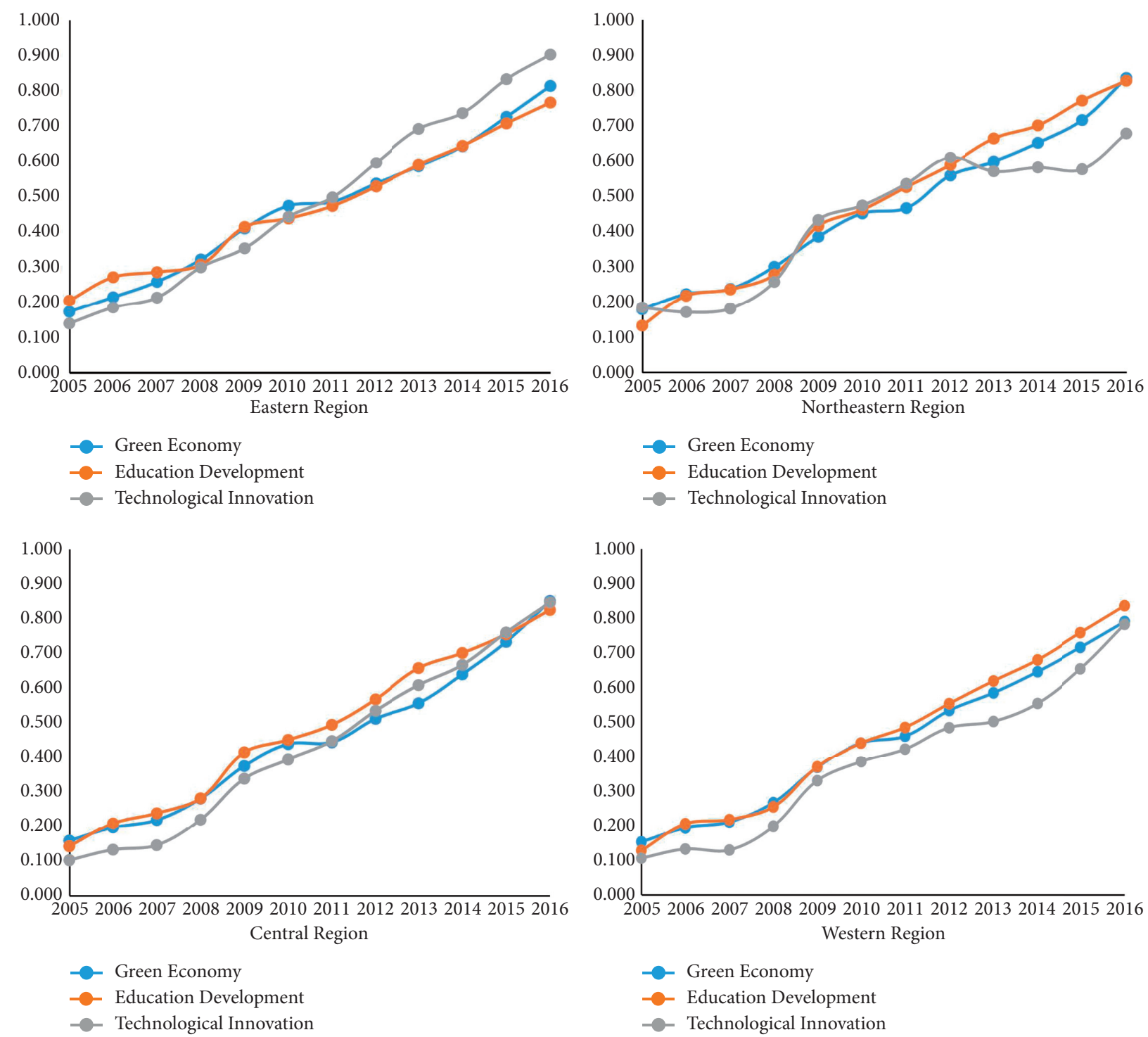

FIGURE 1: Changes in green economy, education development, and technological innovation in different regions from 2005 to 2016.

regions was always lower than that of education development and technological innovation. Finally, it can be seen from Figure 1 that no matter in the eastern region, northeast region, central region, and western region, the fluctuation of the development level of technological innovation from 2005 to 2016 is greater than that of green economy and education development.

4.2. The Coordination Level of Green Economy, Education Development, and Technological Innovation. The coupling coordination level of China's green economy, education development, and technological innovation from 2005 to 2016 can be calculated based on the calculation results of the comprehensive level of China's green economy, education development, and technological innovation from 2005 to 2016 by using formulas (6)-(9). The results are shown in Table 4 . In order to directly analyze the coupling coordination level of green economy, education development, and technological innovation in different regions, the 30 provinces and cities in China are divided into four different regions: the eastern region, the northeast region, the central region, and the western region, and Figure 2 is produced according to the coupling coordination results of green economy, education development, and technological innovation in different regions. The development and change of China's green economy, education development, and technological innovation in different regions from 2005 to 2016 are directly shown in Figure 2.

The green economy, education development, and technology innovation level of coordination is in a rising trend in the different parts of China from 2005 to 2016 from Table 4 and Figure 2; in most of the regions in 2005, the green economy, the coordination of education development, and technological innovation level is lower than 0.1 . That is, in a state of extreme incoordination, more than half of the provinces and cities had a coordination degree of over 0.6 on green economy, education development, and technological 
TABLE 4: Coupling coordination level of green economy, education development, and technological innovation.

\begin{tabular}{|c|c|c|c|c|c|c|c|c|c|c|c|c|c|}
\hline Regions & Province year & 2005 & 2006 & 2007 & 2008 & 2009 & 2010 & 2011 & 2012 & 2013 & 2014 & 2015 & 2016 \\
\hline \multirow{11}{*}{ Eastern region } & Beijing & 0.037 & 0.055 & 0.056 & 0.072 & 0.130 & 0.169 & 0.181 & 0.221 & 0.282 & 0.348 & 0.413 & 0.536 \\
\hline & Tianjin & 0.018 & 0.035 & 0.050 & 0.077 & 0.098 & 0.127 & 0.158 & 0.236 & 0.359 & 0.409 & 0.530 & 0.601 \\
\hline & Hebei & 0.007 & 0.014 & 0.020 & 0.037 & 0.086 & 0.128 & 0.144 & 0.219 & 0.257 & 0.313 & 0.492 & 0.609 \\
\hline & Shandong & 0.008 & 0.016 & 0.025 & 0.048 & 0.088 & 0.127 & 0.157 & 0.216 & 0.286 & 0.382 & 0.515 & 0.662 \\
\hline & Shanghai & 0.015 & 0.029 & 0.049 & 0.069 & 0.116 & 0.168 & 0.201 & 0.229 & 0.281 & 0.357 & 0.464 & 0.631 \\
\hline & Jiangsu & 0.008 & 0.014 & 0.020 & 0.046 & 0.083 & 0.135 & 0.182 & 0.271 & 0.369 & 0.429 & 0.570 & 0.611 \\
\hline & Zhejiang & 0.011 & 0.025 & 0.032 & 0.054 & 0.098 & 0.147 & 0.166 & 0.228 & 0.283 & 0.356 & 0.462 & 0.654 \\
\hline & Fujian & 0.008 & 0.014 & 0.018 & 0.037 & 0.068 & 0.104 & 0.135 & 0.200 & 0.295 & 0.406 & 0.523 & 0.667 \\
\hline & Guangdong & 0.013 & 0.025 & 0.038 & 0.065 & 0.093 & 0.114 & 0.129 & 0.188 & 0.275 & 0.318 & 0.430 & 0.634 \\
\hline & Hainan & 0.003 & 0.007 & 0.011 & 0.029 & 0.086 & 0.144 & 0.181 & 0.255 & 0.334 & 0.367 & 0.491 & 0.536 \\
\hline & Average & 0.012 & 0.023 & 0.031 & 0.053 & 0.095 & 0.136 & 0.164 & 0.227 & 0.303 & 0.371 & 0.492 & 0.618 \\
\hline \multirow{4}{*}{ Northeastern region } & Liaoning & 0.013 & 0.022 & 0.027 & 0.057 & 0.117 & 0.169 & 0.221 & 0.278 & 0.331 & 0.346 & 0.361 & 0.516 \\
\hline & Jilin & 0.006 & 0.013 & 0.015 & 0.022 & 0.088 & 0.109 & 0.141 & 0.236 & 0.233 & 0.293 & 0.381 & 0.585 \\
\hline & Heilongjiang & 0.014 & 0.019 & 0.023 & 0.045 & 0.119 & 0.160 & 0.191 & 0.267 & 0.300 & 0.346 & 0.402 & 0.488 \\
\hline & Average & 0.011 & 0.018 & 0.022 & 0.040 & 0.108 & 0.145 & 0.184 & 0.262 & 0.290 & 0.331 & 0.384 & 0.529 \\
\hline \multirow{7}{*}{ Central region } & & 0.006 & 0.013 & 0.017 & 0.041 & 0.095 & 0.125 & 0.149 & 0.219 & 0.296 & 0.387 & 0.486 & 0.669 \\
\hline & Henan & 0.006 & 0.012 & 0.018 & 0.031 & 0.070 & 0.099 & 0.115 & 0.172 & 0.289 & 0.369 & 0.518 & 0.662 \\
\hline & Hubei & 0.004 & 0.011 & 0.013 & 0.030 & 0.090 & 0.128 & 0.147 & 0.220 & 0.316 & 0.401 & 0.556 & 0.669 \\
\hline & Hunan & 0.003 & 0.008 & 0.013 & 0.032 & 0.081 & 0.102 & 0.125 & 0.198 & 0.299 & 0.386 & 0.537 & 0.675 \\
\hline & Jiangxi & 0.008 & 0.014 & 0.019 & 0.034 & 0.081 & 0.126 & 0.151 & 0.207 & 0.247 & 0.310 & 0.398 & 0.629 \\
\hline & Anhui & 0.005 & 0.011 & 0.015 & 0.026 & 0.072 & 0.099 & 0.129 & 0.190 & 0.249 & 0.366 & 0.519 & 0.688 \\
\hline & Average & 0.006 & 0.013 & 0.017 & 0.034 & 0.085 & 0.118 & 0.143 & 0.210 & 0.284 & 0.364 & 0.485 & 0.647 \\
\hline \multirow{12}{*}{ Western region } & Chongqing & 0.004 & 0.010 & 0.011 & 0.030 & 0.053 & 0.101 & 0.129 & 0.168 & 0.256 & 0.370 & 0.513 & 0.724 \\
\hline & Sichuan & 0.006 & 0.013 & 0.018 & 0.032 & 0.070 & 0.100 & 0.128 & 0.192 & 0.294 & 0.350 & 0.473 & 0.614 \\
\hline & Guizhou & 0.005 & 0.012 & 0.010 & 0.021 & 0.080 & 0.129 & 0.112 & 0.219 & 0.205 & 0.256 & 0.350 & 0.588 \\
\hline & Yunnan & 0.002 & 0.007 & 0.008 & 0.016 & 0.058 & 0.094 & 0.139 & 0.160 & 0.194 & 0.274 & 0.367 & 0.500 \\
\hline & Guangxi & 0.004 & 0.007 & 0.009 & 0.021 & 0.060 & 0.095 & 0.125 & 0.193 & 0.284 & 0.383 & 0.470 & 0.545 \\
\hline & Neimenggu & 0.007 & 0.011 & 0.013 & 0.024 & 0.072 & 0.116 & 0.144 & 0.223 & 0.230 & 0.239 & 0.367 & 0.529 \\
\hline & Shanxi & 0.008 & 0.016 & 0.018 & 0.034 & 0.077 & 0.107 & 0.139 & 0.198 & 0.249 & 0.330 & 0.479 & 0.546 \\
\hline & Gansu & 0.005 & 0.012 & 0.014 & 0.031 & 0.090 & 0.143 & 0.151 & 0.237 & 0.288 & 0.386 & 0.489 & 0.560 \\
\hline & Qinghai & 0.005 & 0.011 & 0.011 & 0.017 & 0.087 & 0.116 & 0.136 & 0.170 & 0.193 & 0.207 & 0.305 & 0.526 \\
\hline & Ningxia & 0.006 & 0.013 & 0.016 & 0.033 & 0.079 & 0.112 & 0.136 & 0.187 & 0.220 & 0.295 & 0.407 & 0.665 \\
\hline & Xinjiang & 0.009 & 0.023 & 0.021 & 0.038 & 0.089 & 0.131 & 0.167 & 0.209 & 0.213 & 0.265 & 0.398 & 0.512 \\
\hline & Average & 0.006 & 0.012 & 0.013 & 0.027 & 0.075 & 0.114 & 0.139 & 0.197 & 0.240 & 0.307 & 0.421 & 0.576 \\
\hline National & The national average & 0.008 & 0.016 & 0.020 & 0.037 & 0.087 & 0.125 & 0.152 & 0.216 & 0.277 & 0.344 & 0.457 & 0.604 \\
\hline
\end{tabular}

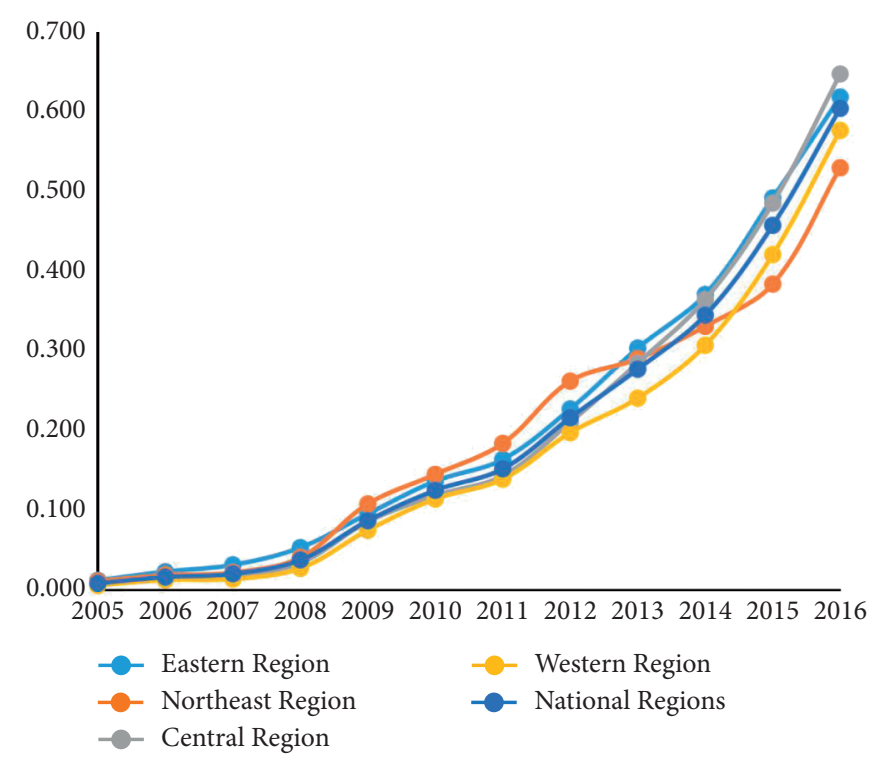

FIgURE 2: Coupling coordination degree of green economy, education development, and technological innovation. innovation in 2016, which means that the coordination level of green economy, education development, and technological innovation in more than half of the country is at the primary coordination level. This shows that China's coordination level of green economy, education development, and technological innovation has been continuously improved from 2005 to 2016 . However, it can be seen from Table 4 and Figure 2 that the coordination level of green economy, education development, and technological innovation in most regions of China is still lower than 0.7 in 2016, which means that there is still a lot of space for improvement in the coordination level of green economy, education development, and technological innovation in China. Therefore, the Chinese government needs to further increase its support for green economy, education development, and technological innovation and strives to enhance the level of coordination between green economy, education development, and technological innovation. The above is an overall analysis of the coordination level of green economy, education development, and technological innovation in China, but it fails to show the specific regional 


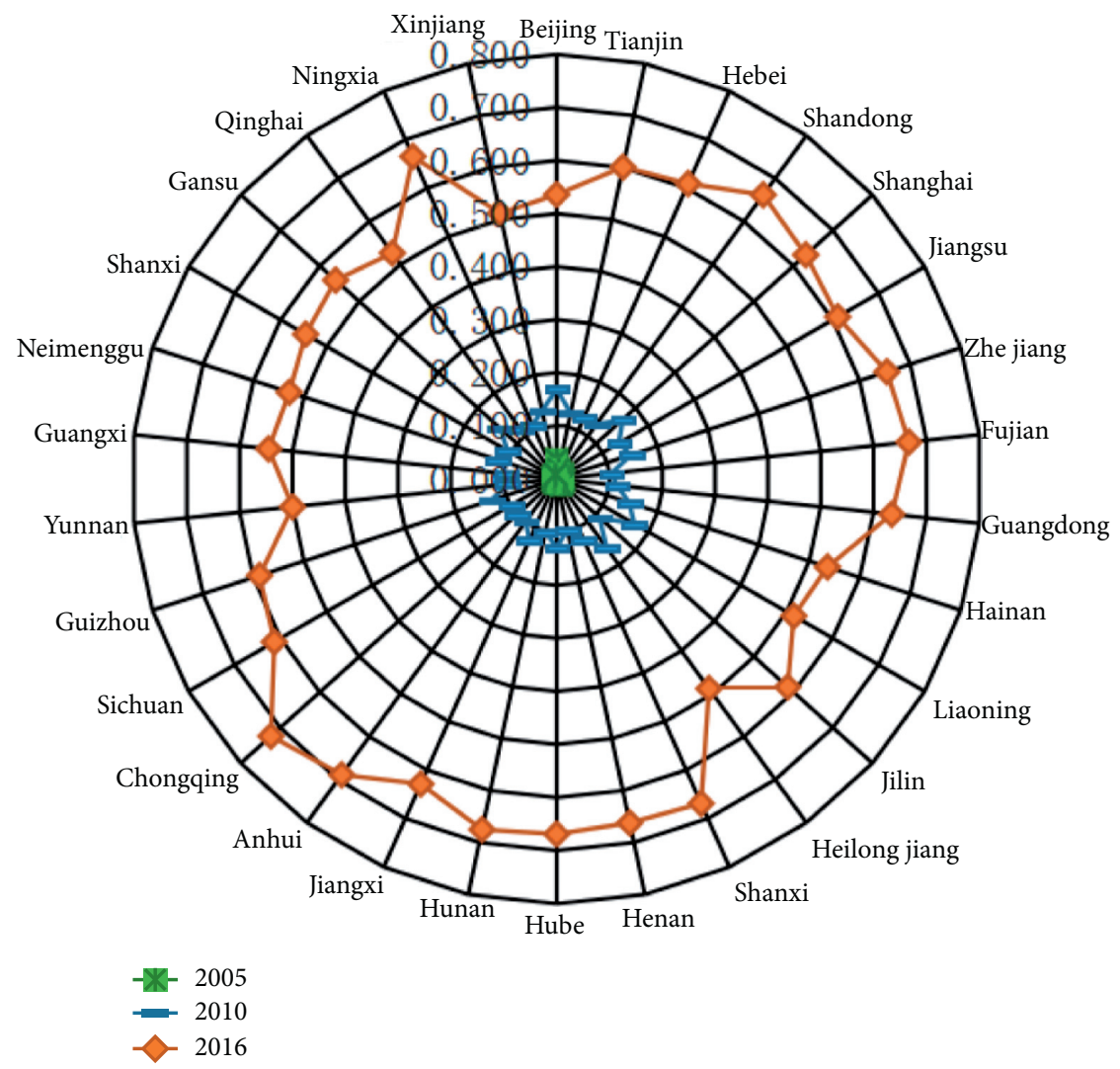

FIGURE 3: Coupling coordination level of green economy, education development, and technological innovation in 2005, 2010 , and 2016.

situation of green economy, education development, and technological innovation in different regions of China in detail. In order to analyze the coordination level of green economy, education development, and technological innovation in different regions of China, Figure 3 is produced based on the measurement results of the coordination level of green economy, education development, and technological innovation in different regions of China in 2005, 2010, and 2016. The temporal and spatial changes of the coupling coordination level of green economy, education development, and technological innovation in China from 2005 to 2016 are shown directly in Figure 3.

That is, the coordination level of green economy, education development, and technological innovation in most regions of China is lower than 0.1 which can be directly found from Figure 3 in 2005. That is, the coordination level of green economy, education development, and technological innovation in all regions of China was in a state of incoordination in 2005. However, after five years of development, the coordination level of green economy, education development, and technological innovation in most regions of China was below 0.2 in 2010, indicating that China did not make great progress in the coordinated development of green economy, education development, and technological innovation from 2005 to 2010 . However, after the development from 2010 to 2016, the coordination level of green economy, education development, and technological innovation in most regions of China exceeded 0.6 in 2016. That means the coordination among green economy, education development, and technological innovation in most regions of China entered a state of slight coordination in 2016. Therefore, we can find that the coordination level of green economy, education development, and technological innovation in most regions of China grew very slowly from 2005 to 2010. However, the coordinated growth rate of green economy, education, and technological innovation in all regions of China from 2010 to 2016 was significantly higher than that from 2005 to 2010 . This is mainly because of the increasingly severe environmental pollution situation in China and the growing downward pressure on economic growth after 2010. The Chinese government has increased its support for green economy, education development, and technological innovation. In addition, China's green economy, coordination of education development, and technological innovation level has certain regional characteristics from Figure 3. For example, the green economy, the coordination level of education development, and technological innovation in the eastern region in 2016 was obviously higher than that in the central region. The coordination level in the central region is significantly higher than that in the northeast region and the western region. These regional characteristics accord with China's economic development level of regional characteristics. That means the east of China's economic development level is higher than that in the central region, and the central region's economic development level is higher than that in the northeast region and the western region. 


\section{Conclusions and Discussion}

This article measures the comprehensive level of green economy, education, and technological innovation in different regions of China and evaluates the level of coordination between them. The research results show that, first, the comprehensive level of green economy, education development, and technological innovation in 30 provinces and cities in China from 2005 to 2016 showed a rising trend. Second, there are some regional differences in the levels of green economy, education development, and technological innovation in different regions. To be specific, the development level of technological innovation in the eastern region was lower than that of green economy and education development before 2011. After 2011, the level of technological innovation in the northeast region was higher than that of green economy and education development before 2012; but after 2012, the level of technological innovation in the northeast region was lower than that of green economy and education development. In addition, the development level of technological innovation in central and western regions was lower than the comprehensive level of education development and technological innovation from 2005 to 2016 . Whether in the eastern region, northeast region, central region, and western region, the fluctuation of the development level of technological innovation from 2005 to 2016 is greater than that of green economy and education development. Third, the coordination level of green economy, education development, and technological innovation in different regions of China is in a rising trend from 2005 to 2016. Fourth, the coordination level of green economy, education development, and technological innovation in most regions of China grew very slowly from 2005 to 2010. However, the coordinated growth rate of green economy, education development, and technological innovation in all regions of China from 2010 to 2016 was significantly higher than that from 2005 to 2010. Fifth, the coordination level of green economy, education development, and technological innovation in the eastern region was significantly higher than that in the central region in 2016, and the coordination level in the central region is significantly higher than that in the northeast region and the western region. These regional characteristics accord with China's economic development level of regional characteristics. That means the east of China's economic development level is higher than that in the central region, and the central region's economic development level is higher than that in northeast China and the west. That is mainly because the eastern and middle areas of China's economic development level significantly higher than that of the northeast and western China. Due to the high level of economic development in the eastern and central regions, the investment in the development of green economy, education development, and technological innovation is also greater, so the coordination level of green economy, education development, and technological innovation in the eastern and central regions is higher than that in the northeast and the western region.

The main contributions of this study are as follows: first, the development level of green economy, education development, and technological innovation in 30 provinces and cities of 4 different regions in China from 2005 to 2016 was calculated through the design index system. Second, the coupling coordination model is used to analyze the coordination levels of green economy, education development, and technological innovation in 30 provinces and cities in China from 2005 to 2016. It is of certain significance in helping China to further promote the coordinated development of green economy, education development, and technological innovation. Despite the importance of this study, there are also some limitations. This study did not focus on different areas within the green economy, coordination of education development, and technological innovation level, and the data availability analysis was limited, so we finally ended in 2016. In the future study, we need to expand the data source and make an in-depth analysis on the coordination level of the provinces and cities within the green economy, education development, and technological innovation. In addition, future research will pay more attention to how education development promotes green economy development and technological innovation and analyze the efficiency of green economy development, education development efficiency, and technological innovation in different regions.

\section{Data Availability}

The data used to support the findings of this study are available from the corresponding author upon request.

\section{Conflicts of Interest}

The authors declare that they have no conflicts of interest.

\section{Authors' Contributions}

J.Q.W and K.Z contributed to the conceptualization and the research design; J.Q.W prepared the original draft; and $K . Z$ reviewed and edited the manuscript. All authors have read and agreed to the published version of the manuscript.

\section{Acknowledgments}

This research was funded by the Fundamental Research Funds for Central Universities of Central China Normal University (no. CCNUTE 2019-01A) and General Program of Humanities and Social Sciences of the Ministry of Education (no. 18YJA880090).

\section{References}

[1] S. Zhao, "Application of human capital theory in China in the context of the knowledge economy," International Journal of Human Resource Management, vol. 19, no. 5, pp. 802-817, 2008.

[2] K. Lv, A. Yu, S. Gong, M. Wu, and X. Xu, "Impacts of educational factors on economic growth in regions of China: a spatial econometric approach," Technological and Economic Development of Economy, vol. 23, no. 6, pp. 827-847, 2017. 
[3] D. T. Rodriguez, "Returns to education of Colombian economists: analysis from the theory of human capital (20092013)," Journal of Economic and Social Thought, vol. 3, no. 1, pp. 139-149, 2016.

[4] D. A. Olaniyan and T. Okemakinde, "Human capital theory: implications for educational development," Pakistan Journal of Social Sciences, vol. 24, no. 2, pp. 157-162, 2008.

[5] W. Gao, X. Ding, R. Chen, and W. Min, "An empirical study of the role of higher education in building a green economy," Sustainability, vol. 11, no. 23, p. 6823, 2019.

[6] Z. Rong and C. Zhao, "Research on the correlation model of vocational talents, population structure and economic development," Wireless Personal Communications, vol. 102, no. 2, pp. 1-12, 2018.

[7] R. Permani, "The role of education in economic growth in east Asia: a survey," Asian-Pacific Economic Literature, vol. 23, no. 1, pp. 1-20, 2009.

[8] W. Qazi, S. A. Raza, and S. T. Jawaid, "Higher education and growth performance of Pakistan: evidence from multivariate framework," Quality and Quantity, vol. 48, no. 3, pp. 1651-1665, 2014.

[9] M. Song and Q. Xie, "How does green talent influence China's economic growth?" International Journal of Manpower, vol. 41, 2019.

[10] Y. Liu and F. Dong, "How technological innovation impacts urban green economy efficiency in emerging economies: a case study of 278 Chinese cities," Resources, Conservation and Recycling, vol. 169, Article ID 105534, 2021.

[11] C. I. Fernandes, P. M. Veiga, J. J. M. Ferreira, and M. Hughes, "Green growth versus economic growth: do sustainable technology transfer and innovations lead to an imperfect choice?" Business Strategy and the Environment, vol. 30, no. 4, pp. 2021-2037, 2021.

[12] C. N. Mensah, X. Long, L. Dauda et al., "Technological innovation and green growth in the organization for economic cooperation and development economies," Journal of Cleaner Production, vol. 240, Article ID 118204, 2019.

[13] G. Petroni, B. Bigliardi, and F. Galati, "Rethinking the Porter hypothesis: the underappreciated importance of value appropriation and pollution intensity," The Review of Policy Research, vol. 36, no. 1, pp. 121-140, 2019.

[14] H. Wang, Z. Chen, X. Wu, and X. Nie, "Can a carbon trading system promote the transformation of a low-carbon economy under the framework of the porter hypothesis? -Empirical analysis based on the PSM-DID method," Energy Policy, vol. 129, pp. 930-938, 2019.

[15] J. Fang, C. Gao, and M. Lai, "Environmental regulation and firm innovation: evidence from national specially monitored firms program in China," Journal of Cleaner Production, vol. 271, Article ID 122599, 2020.

[16] B. l. Yuan, S. G. Ren, X. Hu, and X. Y. Yang, "The difference effect of environmental regulation on two stages of technology innovation in China's manufacturing industry," Frontiers of Engineering Management, vol. 3, no. 1, pp. 24-29, 2016.

[17] J. Liu, "Impact of enterprise human capital on technological innovation based on machine learning and SVM algorithm," Journal of Ambient Intelligence and Humanized Computing, pp. 1-13, 2021.

[18] V. D. Ruijter, P. Halvax, B. Dallemagne, L. Swanström, J. Marescaux, and S. Perretta, "The Business Engineering Surgical Technologies (BEST) teaching method: incubating talents for surgical innovation," Surgical Endoscopy, vol. 29, no. 1, pp. 48-54, 2015.
[19] G. Zhou and S. Luo, "Higher education input, technological innovation, and economic growth in China," Sustainability, vol. 10, no. 8, p. 2615, 2018.

[20] H. Xiao and J. Mao, "Effects of postgraduate education on technological innovation: a study based on the spatial Durbin model," Asia Pacific Education Review, vol. 22, no. 1, pp. 89-99, 2021.

[21] R. Zhang, W. Zhao, and Y. Wang, "Big data analytics for intelligent online education," Journal of Intelligent and Fuzzy Systems, vol. 40, no. 7, pp. 1-11, 2020.

[22] L. Jiang, "Virtual reality action interactive teaching artificial intelligence education system." Complexity, vol. 2021, Article ID 5553211, 11 pages, 2021.

[23] T. Shi, T. Weiteng, W. Zhang, and Q. Zhou, "Spatiotemporal relationship between ecological environment and economic development in tropical and subtropical regions of Asia," Tropical Conservation Science, vol. 12, Article ID $1940082919878961,2019$.

[24] W. Zhang, X. Zhang, M. Zhang, and W. Li, "How to coordinate economic, logistics and ecological environment? evidences from 30 Provinces and Cities in China," Sustainability, vol. 12, no. 3, p. 1058, 2020.

[25] T. Shi, S. Yang, W. Zhang, and Q. Zhou, "Coupling coordination degree measurement and spatiotemporal heterogeneity between economic development and ecological environment ----Empirical evidence from tropical and subtropical regions of China," Journal of Cleaner Production, vol. 244, Article ID 118739, 2020.

[26] C. Hou, H. Chen, and R. Long, "Coupling and coordination of China's economy, ecological environment and health from a green production perspective," International journal of Environmental Science and Technology, pp. 1-20, 2021.

[27] W. Li, P. Yi, D. Zhang, and Y. Zhou, "Assessment of coordinated development between social economy and ecological environment: case study of resource-based cities in Northeastern China," Sustainable Cities and Society, vol. 59, Article ID 102208, 2020.

[28] M. Wu, J. Wu, and C. Zang, "A comprehensive evaluation of the eco-carrying capacity and green economy in the Guangdong-Hong Kong-Macao greater bay area, China," Journal of Cleaner Production, vol. 281, no. 1, Article ID 124945, 2020.

[29] R. Liu, D. Chen, S. Yang, and Y. Chen, "Evaluation of green development efficiency of the major cities in gansu province, China," Sustainability, vol. 13, no. 6, p. 3034, 2021.

[30] X. Lv, X. Lu, G. Fu, and C. Wu, "A spatial-temporal approach to evaluate the dynamic evolution of green growth in China," Sustainability, vol. 10, no. 7, p. 2341, 2018.

[31] M. Nieuwenhuis, A. S. R. Manstead, and M. J. Easterbrook, "Accounting for unequal access to higher education: the role of social identity factors," Group Processes \& Intergroup Relations, vol. 22, no. 3, pp. 371-389, 2019.

[32] Y. Jiang, J. Zhang, and T. Xin, "Toward education quality improvement in China: a brief overview of the national assessment of education quality," Journal of Educational and Behavioral Statistics, vol. 44, no. 6, pp. 733-751, 2019.

[33] A. Belmonte, V. Bove, G. D’Inverno, and M. Modica, "School infrastructure spending and educational outcomes: evidence from the 2012 earthquake in Northern Italy," Economics of Education Review, vol. 75, p. 101951, 2020.

[34] K. S. Kim, "Developmental state policy, educational development, and economic development: policy processes in South Korea, 1961-1979," Education Policy Analysis Archives, vol. 20, no. 1, pp. 49-57, 2012. 
[35] N. Roorda and P. Martens, "Assessment and certification of higher education for sustainable development," Sustainability: The Journal of Record, vol. 1, no. 1, pp. 41-56, 2008.

[36] Q. Yan and R. Hou, "Evaluation of regional scientific and technological innovation capability and empirical research," Agro Food Industry Hi-Tech, vol. 28, no. 1, pp. 3179-3181, 2017.

[37] R. F. Wang and F. Ru, "The regional evaluation model of scientific and technological innovation level," Applied Mechanics and Materials, vol. 411-414, pp. 2516-2520, 2013.

[38] Y. Wang, Q. Deng, and Y. Zhang, "Research on the coupling and coordinated development of marine technological innovation and marine ecological economic development," Journal of Coastal Research, vol. 99, no. SI, pp. 419-427, 2020. 